\title{
Basal and Apical Synapses of CA1 Pyramidal Cells Employ Different LTP Induction Mechanisms
}

\author{
Jane E. Haley, ${ }^{1}$ Eric Schaible, Paul Pavlidis, Alane Murdock, and \\ Daniel V. Madison ${ }^{2}$ \\ Department of Molecular and Cellular Physiology \\ Stanford University School of Medicine \\ Stanford, California 94305
}

\begin{abstract}
Nitric oxide (NO) production has been widely reported to be required for the induction of long-term potentiation (LTP) in hippocampal CA1 cells. Of the two constitutive isoforms of NO synthase, the endothelial form (eNOS) has been implicated in the induction of LTP in these cells. The distribution of eNOS within CA1 cells is not uniform, however, being present in the cell bodies and apical dendrites but absent from the basal dendrites. Using extracellular and intracellular recording techniques, we demonstrate that LTP induction in stratum radiatum synapses (onto apical dendrites) is dependent on NO production, being attenuated by pretreatment with a NOS inhibitor. LTP induced in stratum oriens synapses (onto basal dendrites) is, however, resistant to NOS inhibitors. Both forms of LTP require the activation of $\mathbf{N}$-methyl-D-aspartate (NMDA) receptors because induction of LTP in both stratum radiatum and stratum oriens is blocked by AP5. Thus, it appears that synapses onto apical and basal dendrites of CA1 cells use different cellular mechanisms of LTP induction.
\end{abstract}

\section{Introduction}

The diffusible messenger nitric oxide (NO) may act as an intercellular signal during the induc-

\footnotetext{
${ }^{1}$ Present address: Wellcome Laboratory for Molecular Pharmacology, Department of Pharmacology, University College London, London WC1E 6BT, UK.

${ }^{2}$ Corresponding author.
}

tion of long-term potentiation (LTP) in the hippocampus (Bohme et al. 1991; O'Dell et al. 1991; Schuman and Madison 1991, 1994; Haley et al. 1992 ). Both the neuronal and endothelial forms of NO synthase ( $\mathrm{nNOS} / \mathrm{eNOS}$ ) are present in hippocampal CA1 pyramidal cells (Huang et al. 1993; Chiang et al. 1994; Dinerman et al. 1994; O'Dell et al. 1994; Wendland et al. 1994). The dominant isoform in the induction of LTP within CA 1 may be eNOS as nNOS-deficient mice display normal LTP, the induction of which can be attenuated by pretreatment with NOS inhibitors (O'Dell et al. 1994). The distribution of eNOS within CA1 pyramidal cells is not uniform; the apical dendrites in stratum (s.) radiatum display immunoreactivity for eNOS, whereas the basal dendrites in s. oriens appear to be devoid of the enzyme (Dinerman et al. 1994; O'Dell et al. 1994). Previous studies examining NO involvement in LTP in CA1 have been performed in $\mathrm{s}$. radiatum (for example, Bohme et al. 1991; O'Dell et al. 1991, 1994; Schuman and Madison 1991, 1994; Gribkoff and Lum-Ragan 1992; Haley et al. 1992, 1993; Williams et al. 1993; Lum-Ragan and Gribkoff 1993). Because eNOS appears in apical but not basal dendrites of CA1 pyramidal cells, we hypothesized that LTP in $s$. oriens should differ from that in $s$. radiatum in that it should not be dependent on NO. We have tested this hypothesis by testing whether LTP induction in $s$. oriens is sensitive to selective inhibitors of NOS.

\section{Materials and Methods}

Rat hippocampal slices were prepared from male Sprague-Dawley rats $(130-300 \mathrm{~g})$ as described previously (Madison and Nicoll 1986).

LEARNING \& MEMORY 3:289-295 (C) 1996 by Cold Spring Harbor Laboratory Press ISSN1072-0502/96 \$5.00

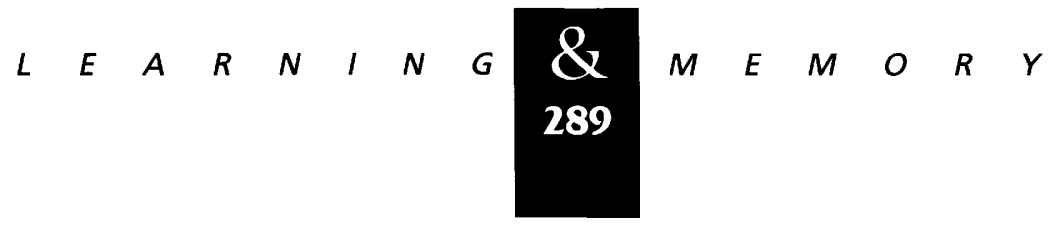


Briefly, rat brains were removed to normal, icecold, artificial cerebrospinal fluid (ACSF) (composition in mM: $119 \mathrm{NaCl}, 2.5 \mathrm{KCl}, 1.3 \mathrm{MgSO}_{4}, 2.5$ $\mathrm{CaCl}_{2}, 1 \mathrm{NaH}_{2} \mathrm{PO}_{4}, 26.2 \mathrm{NaHCO}_{3}, 11$ and D-glucose), sectioned into 500- $\mu \mathrm{m}$ slices, and stored in an interface chamber at room temperature $\left(23 \pm 1^{\circ} \mathrm{C}\right)$. A recovery period of $>1 \mathrm{hr}$ was allowed; slices were then transferred one by one to a submersion-type chamber and maintained at room temperature. Slices were superfused continuously with oxygenated ACSF, and drugs were applied by adding them to this superfusate.

For extracellular field recordings, stimulating and recording electrodes were placed in s. radiatum and in s. oriens of the CA1 region as illustrated for individual experiments. Field and intracellular excitatory postsynaptic potentials (EPSPs) were recorded following alternate stimulation $(100-\mu$ sec duration) of the Schaffer collateral/commissural pathways terminating in either s. oriens or $\mathbf{s}$. radiatum. Intracellular EPSPs were measured in impaled CA1 cells in s. pyramidale with sharp microelectrodes $(\sim 100-150 \Omega$ ) filled with $2 \mathrm{M}$ potassium methylsulfate. In extracellular recordings, the EPSP slope was measured and baseline stimulus intensities set to elicit responses of $\sim 0.2-0.3$ $\mathrm{mV} / \mathrm{ms}$. Intracellular recordings were performed with $50 \mathrm{~mm}$ QX-314 in the electrode to block postsynaptic sodium action potentials. When two stimulating electrodes were used, the independence of the two stimulated pathways was confirmed by demonstrating a lack of paired-pulse facilitation across the two stimulating electrodes. During the experiments, stimuli were alternated, each every $30 \mathrm{sec}$. Stimuli were adjusted to give baseline EPSP amplitudes of $\sim 10 \mathrm{mV}$. LTP was elicited by delivering a tetanus $(100 \mathrm{~Hz}$ for $1 \mathrm{sec}$, four times with an intertrain interval of $15 \mathrm{sec}$ or $30 \mathrm{sec}$ ) through each stimulating electrode in turn. Slices were perfused with either ACSF or ACSF with NO inhibitor for at least $2 \mathrm{hr}$ prior to tetanus.

For blind experiments, one experimenter (ES) made ACSF solutions containing either $100 \mu \mathrm{M}$ $N$-methyl-L-arginine (L-Me-Arg), $100 \mu \mathrm{M}$ D-Me-Arg, $100 \mu \mathrm{M}$ L-NO-Arg, or without NOS inhibitor (sham). Solutions were made fresh before each experiment, and each individual solution was given a computer-generated four-code-letter nonsense code. Coded solutions were given to another experimenter (DM) who applied them to slices and assayed the ability of these slices to produce LTP in response to $s$. radiatum stimulation.
After completion and analysis of all of the individual experiments, ES provided a list of which codes belonged together (i.e., had the same treatment), without revealing the identity of each group. The data were then grouped appropriately for ensemble averaging before the code was broken. All values are expressed as mean \pm s.E.M. Student's paired $t$-tests were used to test significance. $P$ values $>0.05$ were considered not significant.

\section{Results}

\section{BLIND EXPERIMENTS}

Because of the controversy surrounding the ability of NOS inhibitors to prevent the induction of LTP (for example, Chetkovich et al. 1993; Williams et al. 1993; Bannerman et al. 1994a,b; Cummings et al. 1994), we have repeated some of our earlier experiments (from Schuman and Madison 1991), but this time we have done the experiments blind. Stimulating electrodes were placed in s. radiatum on either side of the recording electrode (Fig. 1A) to give two independent synaptic pathways. Figure 1B,C shows a typical experiment in this series. Tetanic stimulation was delivered to one pathway (chosen at random; $100 \mathrm{~Hz}$ for $1 \mathrm{sec}$, 4 trains, 30 sec apart). Application of the unknown drug (or sham) was started 30-60 min after the tetanization of the first pathway. At least $2 \mathrm{hr}$ after the beginning of this drug (or sham) application, the other pathway was tetanized. Experiments were excluded before tetanization if the baseline was insufficiently stable. After first tetanization, experiments were discarded if the tetanized pathway (before application of unknown solution) failed to produce LTP (to ensure that treatment was only given to slices capable of producing potentiation). No experiments were excluded after the unknown solution was applied.

Figure 2 shows the averaged results of the blind NOS inhibitor experiments. LTP was measured $1 \mathrm{hr}$ after tetanic stimulation. In sham treated slices (Fig. 2A), LTP was 139.4 $\pm 6.2 \%$ $(n=8, P<0.002)$ before treatment and 128.6士 $14.9 \%$ after treatment $(n=8, P<0.05)$. Following treatment with L-Me-Arg (Fig. 2B), however, LTP was significantly attenuated, being reduced from $135.2 \pm 9.4 \%(n=10, P<0.002)$ to $110.5 \pm 6.2 \%$ ( $n=10$, not significant). Similarly, after treatment with L-NO-Arg (Fig. 2C), LTP was only $109.7 \pm 6.9 \%(n=8$, not significant $)$ compared with the control value of $148.1 \pm 13.9 \%(n=8$,

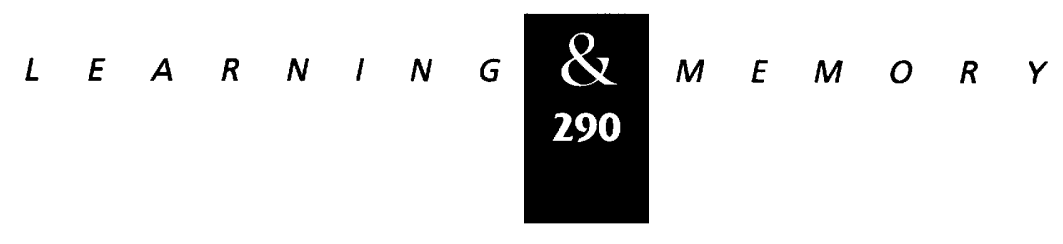




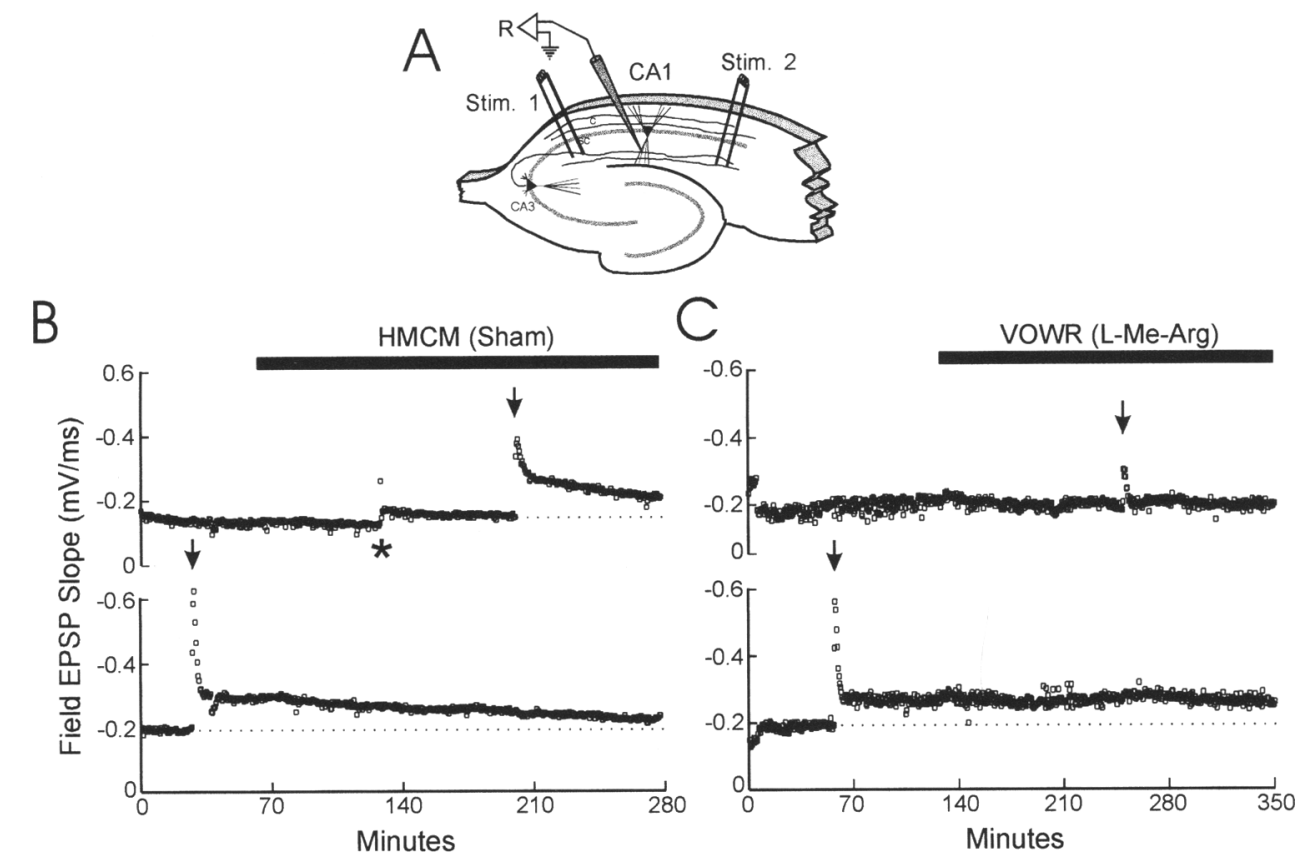

Figure 1: Protocol of blind application of NOS inhibitors to hippocampal slices. (A) Diagram of a hippocampal slice showing the placement of two stimulating electrodes and one recording electrode in s. radiatum. Stim. 1 was placed in the s. radiatum approximately halfway between s. pyramidale and the hippocampal fissure at the CA1/CA2 border. Stim. 2 was similarly placed but at the subiculum end of CA1. Stimuli were delivered alternately through the two stimulating electrodes, and the response taken through the common recording electrode. $(B, C)$ After collection of sufficient baseline, one stimulating electrode was chosen at random for delivery of a tetanic stimulation ( $100 \mathrm{~Hz}$ for $1 \mathrm{sec}, 4 \mathrm{trains}, 30 \mathrm{sec}$ apart). After $\sim 1 \mathrm{hr}$, the unknown solution was applied to the slice for at least $2 \mathrm{hr}$, and then an identical tetanus was delivered through the other stimulating electrode. The recording then continued for another hour. $(B)$ Application of the solution coded HMCM (control ACSF) neither reversed LTP in the first tetanized path, nor did it prevent LTP from occurring in the second stimulated path. Asterisk $\left(^{*}\right)$ indicates where the stimulus was adjusted in the second tetanized pathway to match the baseline size of responses from the first and second pathway. (C) Application of the solution VOWR (L-Me-Arg, $100 \mu \mathrm{M})$ did not reverse LTP induced in the first tetanized path but did prevent LTP in the second tetanized path.

$P<0.02)$ in the same slices. Treatment with D-MeArg (Fig. 2D), the inactive isomer, produced a result not different from sham treatment. LTP in D-Me-Arg was $122.4 \pm 15.9 \%$ of baseline $(n=10$, $P<0.02)$, compared with $137.3 \pm 17.5 \%$ in the controls from the same slices $(n=10, P<0.001)$.

\section{LTP IN S. ORIENS VERSUS S. RADIATUM}

In the next series of experiments, we tested for differences in the NO requirements of LTP in excitatory synapses onto the two different dendritic trees of CA1 pyramidal cells. Simultaneous recordings were made of field EPSPs evoked in s. radiatum and s. oriens. A slightly higher stimulus intensity was required in $s$. oriens to produce evoked EPSPs of the same magnitude as in s. radiatum (s. oriens: $32.4 \pm 3.4 \mu \mathrm{A}, n=8$; s. radiatum: $24.6 \pm 1.9 \mu \mathrm{A}, n=8, P<0.02)$. In control slices, tetanic stimulation resulted in significant potentiation of the EPSP that lasted at least 60 $\mathrm{min}$ in both s. radiatum and s. oriens (s. radiatum: $140.3 \pm 6.7 \%$; s. oriens: $156.0 \pm 13.3 \%$ of pretetanus baseline at $60 \mathrm{~min}$ post-tetanus, $n=9$ ), although the magnitude of LTP in s. oriens was generally greater than in s. radiatum (Fig. 3). Pretreatment of slice with the NOS inhibitor L-NO-Arg attenuated LTP in $s$. radiatum (111.1 $\pm 9.3 \%$, $P=0.02$ compared with control slices, $n=8$ ), whereas s. oriens LTP was intact in the same slices (156.4 $\pm 17.9 \%, n=8$ ) (Fig. 3). Intracellular recordings of CA1 neurons confirmed that LTP induction in $s$. oriens is resistant to inhibition by NOS inhibitors (Fig. 4). In each experiment, stim-

$$
\text { …… 橉 }
$$


Haley et al.

Figure 2: Averaged results of the blind NOS inhibitor experiments. Each graph shows ensemble averages of the slope of EPSP fields taken for the tetanic stimulation given after drug or sham treatment. This is superimposed on the ensemble average of traces taken for the tetanic stimulation before drug or sham treatment in the same slices. Jagged arrow indicates the "after treatment" trace. All treatments were performed blind. (A) Sham treatment: Application of control ACSF did not result in a significant reduction in LTP. (B) L-Me-Arg: Application of $100 \mu \mathrm{M}$ L-Me-Arg produced a significant inhibition of LTP after a 2-hr application. (C) L-NO-Arg $(100 \mu \mathrm{M})$ produced a significant inhibition of LTP. (D) D-Me-Arg: Application of the less active isomer (100 $\mu \mathrm{M})$ did not produce a significant inhibition of LTP.
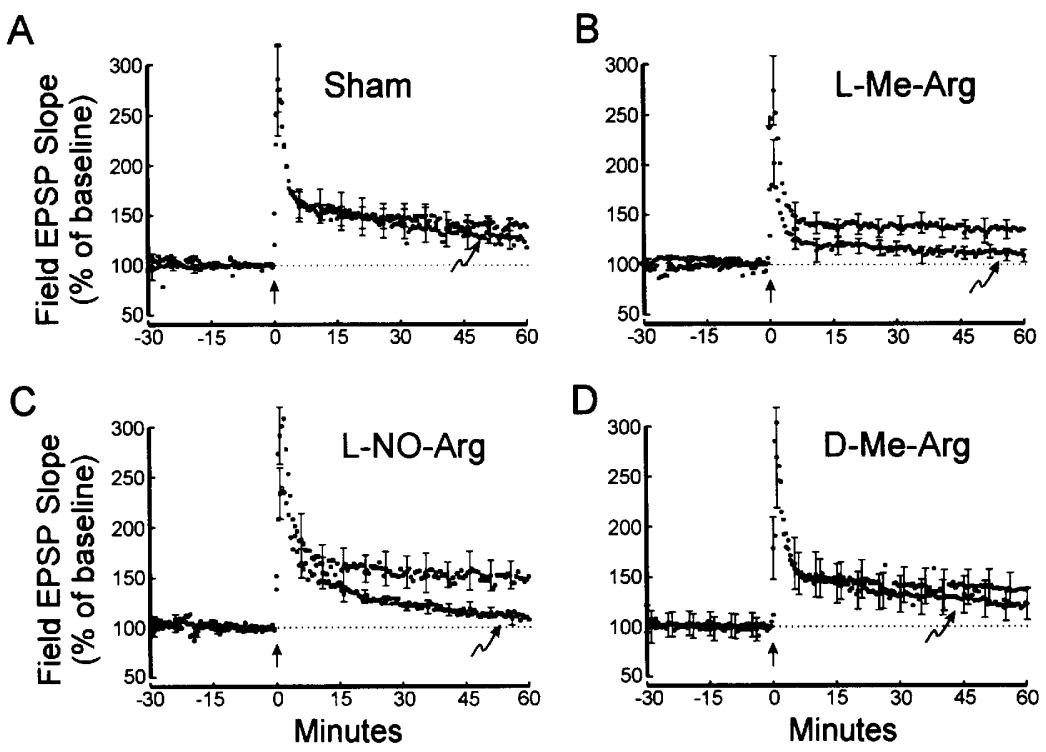

ulus strengths were adjusted to produce roughly equal control EPSPs in s. oriens and s. radiatum ( $\mathrm{s}$. radiatum: $6 \pm 0.04 \mathrm{mV}$; s. oriens: $6 \pm 0.03 \mathrm{mV}$; $n=7)$. In the presence of $100 \mu \mathrm{M}$ L-NO-Arg, tetanic stimulation of $s$. oriens elicited LTP of intracellularly recorded EPSPs $(157.4 \pm 20.7 \%, n=7$, $P<0.05$ ), whereas tetanus of $\mathrm{s}$. radiatum failed to result in significant LTP $(123.4 \pm 13.6 \%, n=7$, $P>0.05$ ).

LTP induction in both s. radiatum and s. oriens requires activation of NMDA receptors. Pretreatment with the NMDA receptor antagonist AP5 blocked LTP induction in both pathways (Fig. 5). A small amount of depression was observed in both pathways (s. radiatum: $82.3 \pm 5.0 \%$ of pretetanus baseline at $15 \mathrm{~min}$ post-tetanus, $P<0.02$, $n=6$; s. oriens: $77.7 \pm 4.5 \%, P<0.01, n=6$ ). Following washout of AP5, LTP could be induced in both $s$. radiatum and $s$. oriens (s. radiatum: $122.2 \pm 4.7 \%$ of pre-second-tetanus baseline at 30 min post-tetanus, $P<0.005, n=6 ;$ s. oriens: $171.3 \pm 16.6 \%, P<0.02, n=6)$.

\section{Discussion}

Our data shows that NO production is used in the induction of LTP in $s$. radiatum but not $s$. oriens of area CA1, because NOS inhibitors attenuate LTP in s. radiatum but not in s. oriens. Furthermore, the conclusion that $s$. radiatum LTP is NO-dependent is bolstered by the finding of our blind experiments. These two forms of LTP reside in synaptic pathways that are anatomically similar, and both require NMDA-receptor activation, unlike the NO-dependent and -independent LTP seen in associational-commissural and mossy fiber synapses of area CA3 (Nicolarakis et al. 1994).

A previous study using nNOS knockout mice has implicated eNOS as the most likely isoform to be involved in NO production during LTP induction in CA1 pyramidal cells (O'Dell et al. 1994). The distributions of nNOS and eNOS are different within the CA1 cells, with nNOS being found in cell bodies (Dinerman et al. 1994) and proximal apical and basal dendrites (Wendland et al. 1994), whereas eNOS is found in cell bodies and in the apical dendrites (Dinerman et al. 1994; O'Dell et. al. 1994). Our physiological findings that LTP is NO-dependent in s. radiatum but NO-independent in s. oriens, under the same experimental conditions, are consistent both with the cellular distribution of the eNOS and for a more central role of eNOS in LTP.

Although our results support a requirement for NO in LTP of s. radiatum, there have been a number of reports that LTP in this region does not require $\mathrm{NO}$ or that it does not require $\mathrm{NO}$ under certain experimental conditions such as elevated experimental temperatures $\left(\sim 30^{\circ} \mathrm{C}\right.$; Williams et al. 1993; Cummings et al. 1994), with GABA antagonists present (O'Dell et al. 1991), in vivo (Bannerman et al. 1994a,b), with weak tetanic

$$
\begin{array}{llllllllllllllll}
\hline & E & A & R & N & I & N & G & \begin{array}{c}
\mathbf{X} \\
\mathbf{2 9 2}
\end{array} & M & E & M & O & R & Y
\end{array}
$$




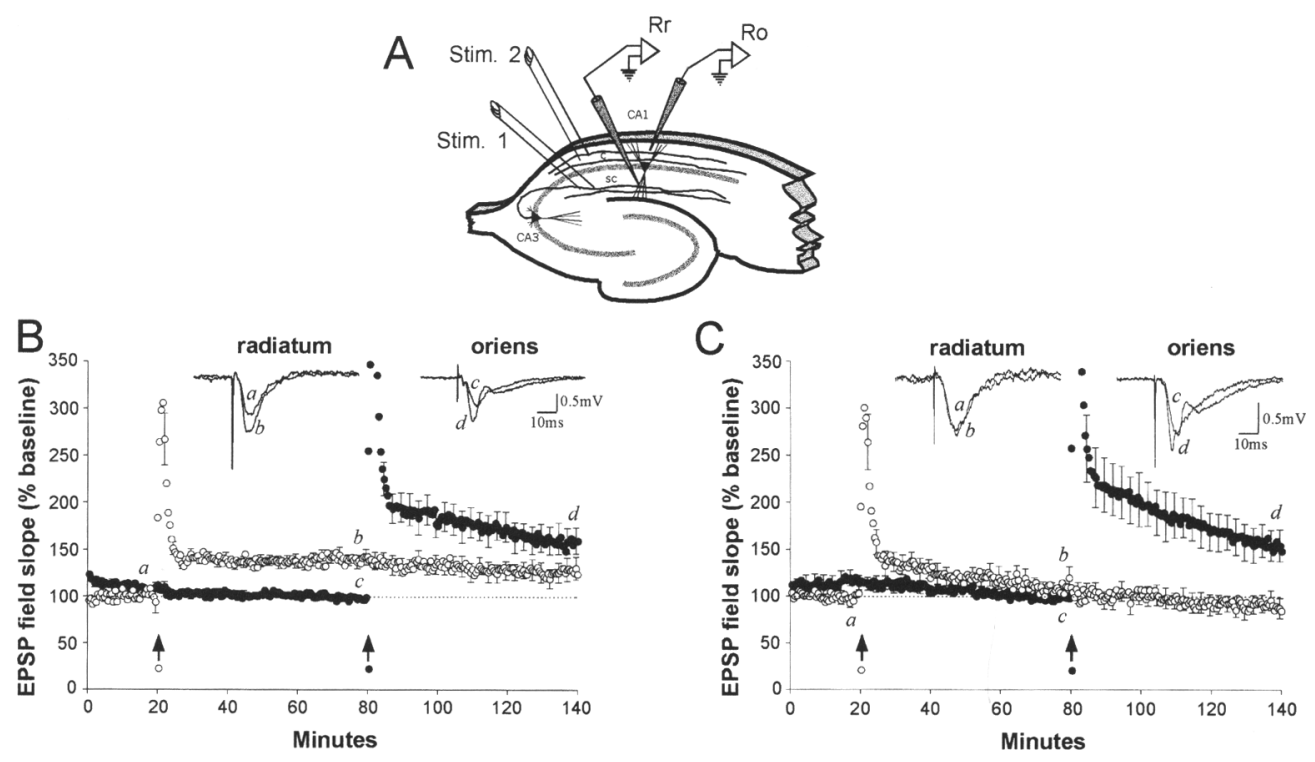

Figure 3: Pretreatment with the NOS inhibitor L-NO-Arg prevents induction of LTP in s. radiatum but not s. oriens. $(A)$ Diagram of a hippocampal slice showing the placement of two recording and two stimulating electrodes. Stim. 1 was placed in the s. radiatum approximately halfway between s. pyramidale and the hippocampal fissure. Stim. 2 was placed in s. oriens approximately halfway between s. pyramidale and the alveus. Both were placed near the CA1/CA2 border. Two field electrodes were placed in mid-CA1, one in $\mathrm{s}$. radiatum and one in s. oriens as shown. $(B, C)$ Pathways were stimulated alternately, and tetanic stimulation was applied at the arrows. (Insets) Representative field EPSP waveforms before and $60 \mathrm{~min}$ following tetanus of the relevant pathway $(\mathrm{a}-\mathrm{d}) .(B)$ In the absence of inhibitor, at 60 min post-tetanus, both $\mathrm{s}$, radiatum and $\mathrm{s}$. oriens EPSP slopes were significantly greater than baseline $(P<0.005, n=9)$. (C) Pretreatment in $100 \mu \mathrm{M}$ L-NO-Arg resulted in significantly increased EPSP slope $60 \mathrm{~min}$ post-tetanus in s. oriens $(P<0.01)$ but not in s. radiatum $(n=8)$. Inhibitor was applied throughout the experiments in C. Student's paired one-tailed t-test on nonnormalized data.

stimulation (Gribkoff and Lum-Ragan 1992; LumRagan and Gribkoff 1993), or with strong tetanic stimulation (Haley et al. 1993). In our current experiments, the stimulus was adjusted to give equalsized control field potentials in s. oriens and $\mathbf{s}$. radiatum. This generally required a higher stimulus intensity to achieve the same field EPSP in s. oriens, raising the possibility that the survival of $s$. oriens LTP in NOS inhibitors could be attributable to a "stronger" tetanus being delivered there. Despite the fact that the field potentials were equal in s. oriens and s. radiatum, differing dendritic morphologies could possibly make an equal-size field potential more effective in causing postsynaptic depolarization and, thus, LTP, in s. oriens. However, because the difference in LTP between $s$. oriens and $s$. radiatum persists in intracellular recordings, where the control EPSPs were matched in depolarizing amplitude, this seems highly unlikely. In addition, a previous study (Williams et al. 1993) has shown, under experimental conditions similar to our own, that LTP of various amplitudes were equally effected by NOS inhibitors.

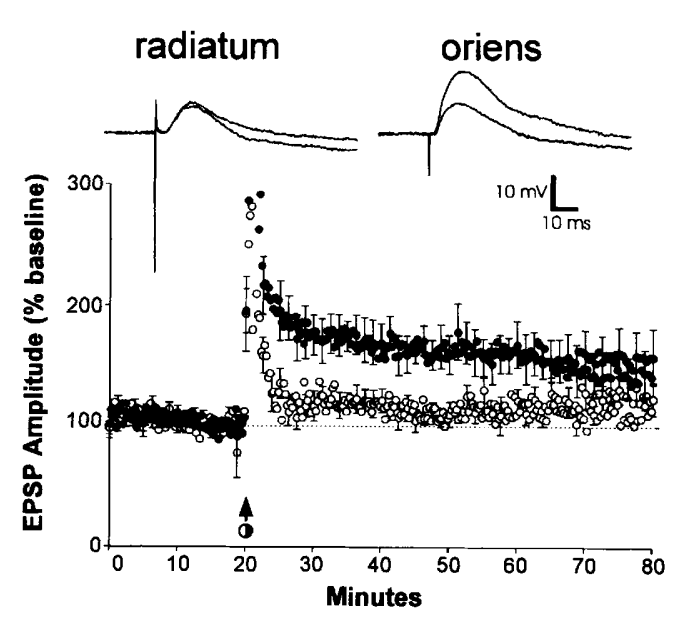

Figure 4: Intracellular recording of $\mathrm{CA} 1$ neuron. The electrode placement is the same as in Fig. 3, except there was only a single recording electrode, intracellular in mid-CA1 s. pyramidale. A 2-hr application of $100 \mu \mathrm{M}$ L-NO-Arg in the perfusate prevented the induction of LTP following tetanus (arrow) in s. radiatum $(O)$ but not s. oriens (1). At 60 min post-tetanus, potentiation above pretetanus baseline was significant in $s$. oriens $(P<0.05)$ but not in s. radiatum $(n=7)$.

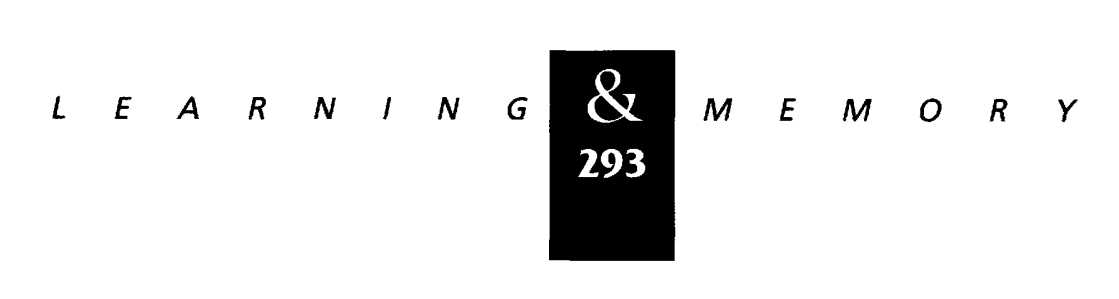


Haley et al.

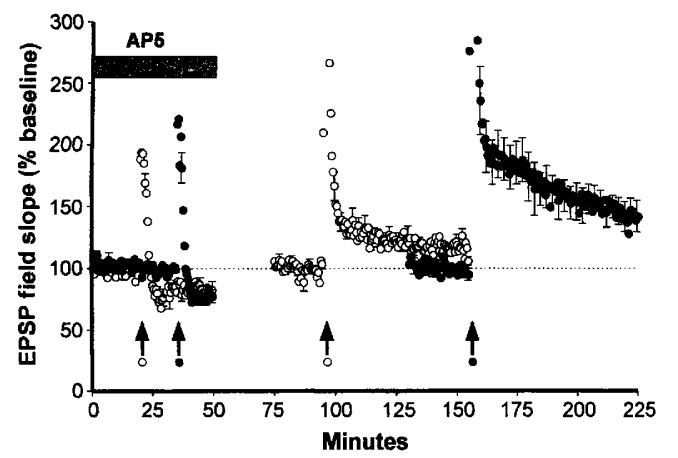

Figure 5: LTP induction in both $\mathrm{s}$. radiatum and $\mathrm{s}$. oriens depends on NMDA receptor activation. AP5 (50 $\mu \mathrm{M})$ prevented LTP induction in both pathways following tetanus (arrows). Washout of the antagonist and applying tetanus again resulted in significant potentiation in s. radiatum $(O, P<0.005)$ and s. oriens $(O, P<0.02)$ $(n=6)$. Data were renormalized following AP5 washout and prior to second tetanus applications, for clarity.

Several possibilities might account for the apparent ability of different experimental conditions to render NOS inhibitor more or less effective. One such explanation is that there may be two forms of LTP in s. radiatum-one that requires NO and one that does not-with each form of LTP being preferentially expressed under different experimental conditions. Arguing against this is that we find NO-insensitive LTP to be largely absent in s. radiatum under the same experimental conditions and in the same slices, where it is fully present in s. oriens. Another explanation could be that experimental conditions that tend to increase the spatial spread of tetanic stimulation may recruit synapses at more distant sites that exhibit NO-independent LTP.

It is interesting to speculate on whether the mechanistic differences between these two sets of synapses reside in the pre- or postsynaptic cell. However, there is no particularly telling information about this issue in these data. One obvious difference between the $\mathbf{s}$. radiatum and $\mathrm{s}$. oriens is the lack of NO in the postsynaptic dendrites of $\mathbf{s}$. oriens. However, the mere lack of NO does not provide any information about the mechanism of LTP in the s. oriens. Because the presynaptic terminals in s. oriens and s. radiatum arise mostly from contralateral and ipsilateral CA3 pyramidal cells, respectively (Blackstad 1956; Swanson et al. 1978; Laurberg 1979; Van Groen and Wyss 1988; Ishizuka et al. 1990), there is also no reason to suppose that there are presynaptic mechanistic differences in the two sets of synapses. Given the anatomical similarity of inputs to $s$. radiatum and $s$. oriens, the question arises as to just how different the LTPs found in these two areas are. The differences between s. oriens and s. radiatum LTP do not extend to all aspects of the induction process as LTP in both pathways is blocked by pretreatment with the NMDA receptor antagonist AP5. Thus, these two forms of LTP may be essentially identical, differing only in that the role of NO is simply filled by another similar molecule in $\mathbf{s}$. oriens. Alternately, the difference may be more fundamental in that whatever process is subserved by NO in s. radiatum is absent from LTP in s. oriens. For example, in s. radiatum, LTP may use a retrograde messenger, whereas s. oriens does not.

The fact that there are two types of LTP raises the possibility that they might process information differently or be differentially modulated. It remains to be determined what purpose could be served by a system that discriminates between inputs onto different dendrites. It should be noted, however, that the proportion of terminals arising from the contralateral CA4/CA3 cells in the rat is higher in s. oriens than in s. radiatum (Swanson et al. 1978; Laurberg 1979; Van Groen and Wyss 1988). Thus, one possibility is that the two types of LTP serve to process the inputs arriving from the two sides of the brain differently. LTP in s. radiatum can be communicated between synapses on different cells by a mechanism that depends on NO. It will be interesting to test whether this distribution of LTP is absent from synapses that do not utilize NO. This would confer fundamentally different properties on activity-dependent plasticity in synapses on different dendritic trees of the same cell.

\section{Acknowledgments}

We thank M. Bieda for useful discussions. J.E.H. was supported by a North Atlantic Treaty Organization fellowship from the Science and Engineering Council of Great Britain. This work was supported by the Lucille P. Markey Charitable Trust and by grant MH48108 to D.V.M.

The publication costs of this article were defrayed in part by payment of page charges. This article must therefore be hereby marked "advertisement" in accordance with 18 USC section 1734 solely to indicate this fact.

\section{References}

Bannerman, D.M., P.F. Chapman, P.A. Kelly, S.P. Butcher, and R.G. Morris. 1994a. Inhibition of nitric oxide synthase

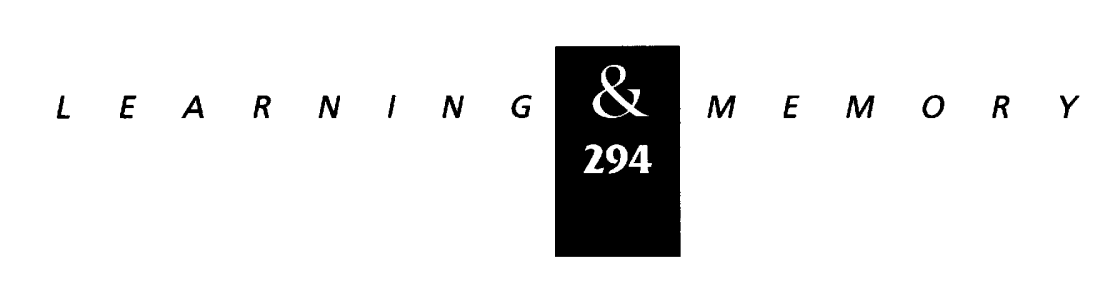


does not prevent the induction of long-term potentiation in vivo. J. Neurosci. 14: 7415-7425.

Bannerman, D.M., S.P. Butcher, and R.G. Morris. 1994b. Intracerebroventricular injection of a nitric oxide synthase inhibitor does not affect long-term slope potentiation in vivo. Neuropharmacology 33: 1387-1397.

Blackstad, T.W. 1956. Commissural connections of the hippocampal region in the rat, with special reference to their mode of termination. I. Comp. Neurol. 105: 417-537.

Bohme, G.A., C. Bon, J.M. Stutzmann, A. Doble, and J.C. Blanchard. 1991. Possible involvement of nitric oxide in long-term potentiation. Eur. J. Pharmacol. 199: 379-381.

Chiang, L.W., F.E. Schweizer, R.W. Tsien, and H. Schulman. 1994. Nitric oxide synthase expression in single hippocampal neurons. Mol. Br. Res. 27: 183-188.

Chetkovich, D.M., E. Klann, and J.D. Sweatt. 1993. Nitric oxide synthase-independent long-term potentiation in area CA1 of hippocampus. NeuroReport 4: 919-922.

Cummings, J.A., S.M. Nicola, and R.C. Malenka. 1994. Induction in the rat hippocampus of long-term potentiation (LTP) and long-term depression (LTD) in the presence of a nitric oxide synthase inhibitor. Neurosci. Lett. 176: 110-114.

Dinerman, J.L., T.M. Dawson, M.J. Schell, A. Snowman, and S.H. Snyder. 1994. Endothelial nitric oxide synthase localized to hippocampal pyramidal cells: Implications for synaptic plasticity. Proc. Natl. Acad. Sci. 91: 4214-4218.

Gribkoff, V.K. and J.T. Lum-Ragan. 1992. Evidence for nitric oxide synthase inhibitor-sensitive and insensitive hippocampal synaptic potentiation. /. Neurophysiol. 68: 639-642.

Haley, J.E., G.L. Wilcox, and P.F. Chapman. 1992. The role of nitric oxide in long-term potentiation. Neuron 8: 211-216.

Haley, J.E., P.L. Malen, and P.F. Chapman. 1993. Nitric oxide synthase inhibitors block LTP induced by weak, but not strong, tetanic stimulation at physiological brain temperatures in rat hippocampal slices. Neurosci. Lett. 160: $85-88$.

Huang, P.L., T.M. Dawson, D.S. Bredt, S.H. Snyder, and M.C. Fishman. 1993. Targeted disruption of the neuronal nitric oxide synthase gene. Cell 75: 1273-1286.

Ishizuka, N., J. Weber, and D.G. Amaral. 1990 Organization of intrahippocampal projections originating from CA3 pyramidal cells in the rat. J. Comp. Neurol. 295: 580-623.

Laurberg, S. 1979. Commissural and intrinsic connections of the rat hippocampus. J. Comp. Neurol. 184: 685-708.

Lum-Ragan, J.T. and V.K. Gribkoff. 1993. The sensitivity of hippocampal long-term potentiation to nitric oxide synthase inhibitors is dependent upon the pattern of conditioning stimulation. Neuroscience 57: 973-983.

Madison, D.V. and R.A. Nicoll. 1986. Actions of noradrenaline recorded intracellularly in rat hippocampal CA1 pyramidal neurones, in vitro. J. Physiol. 372: 221-244.

Nicolarakis, P.J., Y.Q. Lin, and M.R. Bennett. 1994. Effect of nitric oxide synthase inhibition on long-term potentiation at associational-commissural and mossy fibre synapses on CA3 pyramidal neurones. Br. J. Pharmacol. 111: 521-524.

O'Dell, T.J., R.D. Hawkins, E.R. Kandel, and O. Arancio. 1991. Tests on the roles of two diffusible substances in long-term potentiation: Evidence for nitric oxide as a possible early retrograde messenger. Proc. Natl. Acad. Sci. 88: $11285-11289$.

O'Dell, T.J., P.L. Huang, T.M. Dawson, J.L. Dinerman, S.H. Snyder, E.R. Kandel, and M.C. Fishman. 1994. Endothelial NOS and the blockade of LTP by NOS inhibitors in mice lacking neuronal NOS. Science 265: 542-546.

Schuman, E.M. and D.V. Madison. 1991. A requirement for the intercellular messenger nitric oxide in long-term potentiation. Science 254: 1503-1506.

1994. Locally distributed synaptic potentiation in the hippocampus. Science 263: 532-536.

Swanson, L.W., J.M. Wyss, and W.M. Cowan. 1978. An autoradiographic study of the organization of intrahippocampal association pathways in the rat. J. Comp. Neurol. 181: 681-716.

Van Groen, T. and J.M. Wyss. 1988. Species differences in hippocampal commissural connections: Studies in rat, guinea pig, rabbit, and cat. J. Comp. Neurol. 267: 322-334.

Wendland, B., F.E. Schweizer, T.A. Ryan, M. Nakane, F. Murad, R.H. Scheller, and R.W. Tsien. 1994. Existence of nitric oxide synthase in rat hippocampal pyramidal cells. Proc. Natl. Acad. Sci. 91: 2151-2155.

Williams, J.H., Y.G. Li, A. Nayak, M.L. Errington, K.P. Murphy, and T.V. Bliss. 1993. The suppression of long-term potentiation in rat hippocampus by inhibitors of nitric oxide synthase is temperature and age dependent. Neuron 11: 877-884.

Received October 7, 1996; accepted in revised form November 8, 1996.

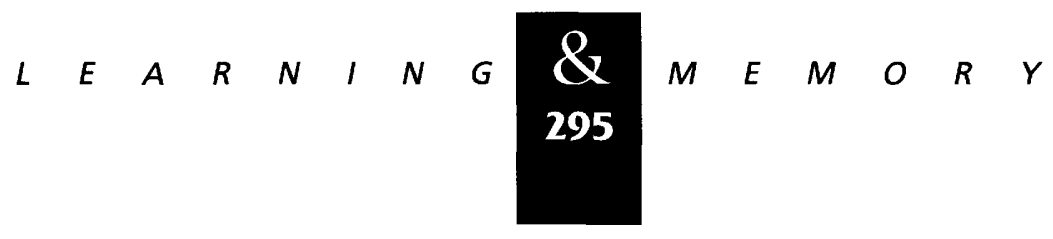




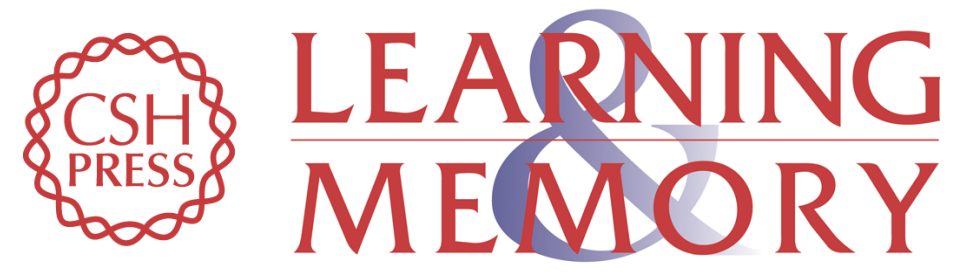

\section{Basal and apical synapses of CA1 pyramidal cells employ different LTP induction mechanisms.}

J E Haley, E Schaible, P Pavlidis, et al.

Learn. Mem. 1996, 3:

Access the most recent version at doi:10.1101//m.3.4.289

References This article cites 25 articles, 7 of which can be accessed free at: http://learnmem.cshlp.org/content/3/4/289.full.html\#ref-list-1

License

Email Alerting Receive free email alerts when new articles cite this article - sign up in the box at the Service top right corner of the article or click here. 